\title{
Leitura de histórias e evocação de estados mentais por pré-escolares
}

\author{
Marisa Cosenza Rodrigues \\ Mariana Wierman Henriques \\ Marina de Oliveira Patrício
}

\begin{abstract}
Resumo
Esta pesquisa visou investigar a evocação de termos mentais por pré-escolares de 5 e 6 anos na leitura de um livro infantil nacional contendo narrativa por imagem (Truks - Editora Ática). Os relatos individuais das crianças, selecionadas por faixa etária, foram gravados, transcritos e analisados identificando-se palavras e expressões voltadas para os estados mentais mediante 4 categorias: termos cognitivos, emocionais, de desejo/intenção e perceptivos. Os resultados indicaram que as crianças de ambas as idades utilizaram termos referentes a estados mentais na leitura de narrativa por imagem. Os termos mais evocados foram os perceptivos, seguidos dos emocionais, cognitivos e de desejo/intenção. Houve diferença significativa entre o número total de termos evocados pelas crianças de 6 anos (264) e as de 5 anos (183). A predominância de termos perceptivos indica que as crianças focalizaram em suas narrativas mais termos que denotam comportamentos físicos e ações das personagens do que propriamente estados subjetivos.
\end{abstract}

Palavras-chave: Filosofia da mente, educação infantil, literatura infantil.

\section{Story reading and evocation of mental terms by pre-school children}

\begin{abstract}
This work is an investigation of the mental terms evoked by preschool children from 5 and 6 years old during the reading of an illustrated children book. (Truks - Publisher Ática). The individual stories of the children, selected according to their age, had been recorded, transcribed and analyzed. It was possible to identify words and expressions related to mental states through four categories: cognitive and emotional terms, wishes/intention and perceptions. The results indicated that the children of both ages used terms concerning to mental states in the reading of narrative with image. The most evoked terms were the wishes/intention and perceptions, followed emotional, cognitive. There were significant difference between the total numbers of terms evoked by those of 6 years (264) and those of 5 years old (183). The predominance of perceptive terms indicates that the children focused on their narratives terms that denote more physical behaviours and actions of the characters than subjective states.
\end{abstract}

Words key: Philosophy of mind, early chilhood education, infantile literature.

\section{Lectura de cuentos y evocación de estados mentales por pre-escolares}

\section{Resumen}

Esta investigación buscó averiguar la evocación de términos mentales por pre-escolares de 5 y 6 años en la lectura de un libro infantil nacional que contiene narrativa por imagen (Trucks - Editora Ática). Los relatos individuales de los niños, seleccionados por edad, fueron gravados, transcritos y analizados identificándose palabras y expresiones dirigidas a los estados mentales mediante 4 categorías: términos cognitivos, emocionales, de deseo/intención y perceptivos. Los resultados indicaron que los niños de ambas edades utilizaron términos referentes a estados mentales en la lectura de narrativa por imagen. Los términos más evocados fueron los perceptivos, seguidos de los emocionales, cognitivos y de deseo/intención. Hubo una diferencia significativa entre el número total de términos evocados por los niños de 6 años (264) y los de 5 años (183). La predominancia de términos perceptivos indica que los niños concentraron en sus narrativas más términos que denotan comportamientos físicos y acciones de los personajes que propiamente estados subjetivos.

Palabras-clave: Filosofia de la mente, educación infantil, literatura infantil. 


\section{Introdução}

Um dos fatores fundamentais para a integração e o convívio social dos indivíduos é a habilidade de compreender estados mentais, ou seja, a capacidade de compreender pensamentos, sentimentos, desejos, crenças e intenções. De Jou e Sperb (1999) salientam que o conhecimento da mente por ser subjetivo e privativo é algo intrínseco à natureza da existência humana. De acordo com Flavell, Miller e Miller (1993/1999), quando a criança entende o funcionamento de sua mente torna-se capaz de compreender eventos cotidianos que envolvem outras pessoas. Este entendimento oferece às crianças explicações do comportamento do outro permitindo prever suas ações no cotidiano da vida diária. Nesta tentativa de compreensão, as crianças elaboram uma teoria sobre os próprios estados mentais e o dos outros "expressando um conjunto de hipóteses que a literatura vem designando como teoria da mente" (Domingues \& Maluf, 2008, p. 12). Astington e Pelletier (2000) salientam que "uma teoria da mente prediz e explica a ação humana, apelando para os estados mentais" (p. 494).

Há uma crescente evidência de que a habilidade para utilizar uma teoria de senso comum da mente emerge nos anos pré-escolares. Por volta de mais ou menos 4 anos de idade a criança apresentaria uma teoria da mente que a capacitaria a prever ações e emoções a partir da percepção e entendimento das crenças e desejos de outras pessoas (Rodrigues, 2004).

Delimitar a idade em que emerge a teoria da mente é um dos problemas que tem ocupado atualmente os pesquisadores. De acordo com Lourenço (1992) a definição sobre quando a criança possui uma teoria da mente está associada ao que os teóricos entendem por teoria da mente. Há teóricos que consideram que a criança possui uma teoria da mente quando consegue atribuir estados mentais a si própria e aos outros, neste caso há estudos demonstrando que essa capacidade já aparece em crianças a partir dos dois ou três anos de idade (Bretherton \& Beeghly, 1982; Brown \& Dunn, 1991; Dunn, Bretherton, \& Munn, 1987; Shatz, Wellman, \& Silber, 1983; Tager-Flusberg, 1992).

Segundo Astington e Pelletier (2000), toda linguagem constitui uma linguagem da mente, visto que o estado mental está presente no ato da fala e, portanto, em toda comunicação verbal. Nesse sentido, "linguagem da mente" refere-se ao uso explícito de termos semânticos que a criança utiliza para se referir aos estados mentais das pessoas crenças, desejos, intenções e emoções. Para Astington e Baird (2005), o estudo da relação entre linguagem e teoria da mente é fundamental para se compreender como as crianças adquirem uma teoria da mente.

Bretherton e Beeghly (1982) foram os pioneiros nos estudos da aquisição da habilidade de falar sobre estados internos em crianças. No estudo dos autores, foram analisadas falas de 30 crianças com idade entre 28 e 30 meses, por meio de relatos obtidos tanto pelas mães quanto por observações diretas. As palavras referentes a estados internos foram divididas em 6 categorias: percepção, fisiologia, afeto, vontade e habilidade, cognição, julgamento moral e obrigação. Os resultados obtidos indicaram que a habilidade da criança para analisar os objetivos e motivos de outros já está razoavelmente bem desenvolvida no terceiro ano de vida; os termos referindo-se à vontade, percepção e estados fisiológicos foram mais presentes no vocabulário destas crianças do que os termos sobre afeto e obrigação moral.

Entretanto, pesquisas longitudinais indicam que por volta dos 2 anos de idade, as crianças adquirem a habilidade de falar sobre verbos mentais, mas não adquirem uma compreensão desses verbos. Shatz et al. (1983) realizaram dois estudos para avaliar a habilidade da criança pequena de comunicar sobre estado mental. O primeiro estudo descreveu a frequência de verbos da referência mental como pensar e saber no discurso de uma criança de 2 anos e 4 meses até os 4 anos. O segundo examinou amostras mais curtas do discurso coletado de 30 crianças de 2 anos de idade sobre um período de 6 meses. Os dados indicaram que as primeiras tentativas na referência a estados mentais começam a aparecer em algumas crianças por volta da segunda metade do terceiro ano e que a ausência de referências mentais nas falas das crianças mais novas sugere a falta da consciência do uso de termos mentais para se referir a estados internos.

Pesquisas posteriores, ainda interessadas na idade de aquisição da habilidade de falar sobre estados mentais, demonstram que os verbos mentais já estão presentes nas conversações de crianças a partir dos 24 meses, corroborando o estudo realizado por Bretherton e Beeghly (1982). Dunn et al. (1987) analisando conversações entre mães e filhos pequenos, realizaram dois estudos longitudinais sobre o desenvolvimento da comunicação verbal de estados de sentimentos. Os estudos apontaram que aos 2 anos de idade, a maioria das crianças faz referência a estados de sentimento numa variedade de contextos, incluindo brincadeiras de faz-de-conta. As crianças mais velhas (25 e 32 meses) apresentaram uma compreensão dos estados mentais próprios e dos outros e entenderam como usar os estados mentais em seus relacionamentos interpessoais. Constatou-se que tanto mães como irmãos mais velhos mencionavam estados de sentimento mais frequentemente com meninas que com meninos; aos 24 meses, as meninas se referiam a estados de sentimento com frequência significativamente maior que os meninos. Os autores salientam que as crianças deram um passo importante na compreensão de que os outros podem ter experiências conscientes semelhantes as suas e reconheceram que esta compreensão pode ser compartilhada com os outros pela linguagem.

Brown e Dunn (1991), tendo como foco a influência do processo de socialização no desenvolvimento precoce das falas sobre desejos, percepções e estados mentais, realizaram uma análise contextual de termos mentais em conversações domésticas. O estudo foi realizado com seis crianças (que eram o segundo filho) observadas durante um período de dois meses - aos 24 e 36 meses - com suas 
mães e irmãos mais velhos. Foram observadas mudanças evolutivas nas falas das crianças que passaram a utilizar mais termos em suas discussões reflexivas, referindose mais aos estados internos dos outros e se esforçando para manipular a percepção e o comportamento dos outros por meio de referências a causas e consequências. Os resultados reforçaram a premissa de que a interação social possui papel fundamental no desenvolvimento infantil relativo ao conhecimento e à compreensão dos estados internos.

Outra abordagem envolvendo o estudo da aquisição de uma teoria da mente e a linguagem foi desenvolvida por Tager-Flusberg (1992), partindo da hipótese central de que a criança autista apresenta déficits na aquisição de uma teoria da mente. A autora comparou os relatos de seis crianças autistas e de seis crianças com síndrome de Down. Conversas espontâneas das crianças com suas mães foram analisadas a partir de quatro categorias de estados psicológicos: desejo, percepção, emoção e cognição. Os resultados obtidos indicaram que o autismo não está relacionado a um déficit primário na área das emoções, como proposto por pesquisas anteriores, pois as crianças autistas podem conversar sobre emoções, usando vários termos lexicais ou discutindo os precedentes ou as consequências das emoções, e que elas são capazes de utilizar termos mentais. Devido às deficiências na habilidade de comunicação e atenção, possuem, no entanto, dificuldades na compreensão dos estados mentais.

Por outro lado, como salientam De Jou e Sperb (1999), há autores que consideram que a criança apresenta uma teoria da mente quando compreende que a tarefa de falsa crença se trata de uma crença diferente da realidade e, portanto, da crença dos outros. É, nesse momento, que esses autores reconhecem a existência de uma teoria da mente que permite à criança colocar-se no lugar do outro. As autoras, como também Domingues e Maluf (2008), Maluf, Deleau, Panciera, Valério e Dominguez (2004), destacam que as primeiras pesquisas nacionais sobre teoria da mente, desenvolvidas na década de 90, inserem-se nessa linha de investigação, pois focalizam o paradigma da falsa crença.

De um modo geral, estes estudos, corroborando pesquisas internacionais, apresentam resultados evidenciando que as crianças mais velhas (a partir dos 4 anos) obtêm melhor desempenho. Porém, os resultados também indicaram que existe uma diferença na comparação entre crianças de diferentes meios socioculturais, com desvantagem para as crianças de meios sociais desprivilegiados (Dias, 1993; Dias, Soares, \& Sá, 1994; Roazzi \& Santana, 1999). O estudo de Roazzi e Santana (2005) demonstra que fatores como idade e nível socioeconômico são aspectos importantes no desempenho das tarefas de falsa crença. Como ressaltam Maluf e cols. (2004), as pesquisas brasileiras têm focalizado aplicações de tarefas envolvendo a elaboração de crença falsa e a compreensão dos atos de comunicação intencional, mas há carência de estudos na literatura nacional com enfoque longitudinal ou de intervenção.

\section{Compreensão dos estados mentais e histórias infantis}

Alguns pesquisadores americanos desenvolveram estudos para investigar o potencial dos livros de histórias infantis como fonte de compreensão e conhecimento dos estados mentais (Cassidy e cols., 1998; Dyer, Shatz, \& Wellman, 2000). Cassidy e cols. (1998) encontraram, em $78 \%$ da amostra de 317 livros lidos por 47 crianças pré-escolares, referência à linguagem de estado interno, indicando que termos voltados para os estados mentais integram a literatura dirigida a esse público infantil. Resultado semelhante foi obtido por Dyer e cols. (2000) que verificaram a ocorrência de palavras e expressões no texto indicando estados mentais, a convergência entre figura e estado mental, as situações de ironia e as de crença falsa. Foram consideradas quatro categorias de estados mentais: termos cognitivos, emocionais, de desejo/intenção e avaliação moral/obrigação. Os resultados também evidenciaram que os livros infantis estão repletos de termos e expressões voltados para os estados mentais, fazendo referência explícita aos pensamentos, sentimentos e intenções dos personagens, contribuindo assim para o desenvolvimento de uma teoria da mente nas crianças.

De acordo com Rodrigues (2004), os livros de histórias infantis ao focalizarem suas ações e interações em pessoas ou animais personificados podem contribuir à compreensão infantil de conteúdos relacionados à mente. A leitura dos livros de histórias para as crianças apresenta oportunidades particularmente úteis para o desenvolvimento da teoria da mente, na medida em que podem promover conversações reflexivas sobre os estados mentais por meio da história. Nesta perspectiva de investigação, estudo realizado pela autora e outros colaboradores (Rodrigues, Oliveira, Rubac, \& Tavares, 2007) baseado nas pesquisas de Cassidy e cols. (1998) e Dyer e cols. (2000), investigou a ocorrência de termos mentais em uma amostra de 100 livros nacionais de histórias infantis. Os resultados convergem com os estudos internacionais apontando que livros infantis nacionais apresentam também um alto índice de referência aos estados mentais $(92 \%)$, com predominância de termos emocionais $(41 \%)$, seguido de termos cognitivos $(39 \%)$, indicando que termos voltados para estados mentais também integram as narrativas dos livros nacionais com significativa frequência. O estudo evidenciou ainda a qualidade das ilustrações como recurso adicional para a compreensão dos estados mentais na medida em que $76 \%$ das figuras analisadas apresentaram convergência com os estados mentais focalizados.

O presente estudo constitui uma proposta de aprofundamento e diversificação desta temática propondose a pesquisar não os livros em si, mas a leitura de crianças pré-escolares considerando, para isso, livros infantis que trazem somente imagens, definidos como narrativas por imagens. De acordo com Valle (2001) e Villardi (1999), essas obras surgidas a partir da década de 70 do século passado, apresentam somente imagens visuais, estabelecendo uma estreita relação com o cotidiano infantil e oferecendo à 
criança oportunidade de imaginar acontecimentos e produzir relatos a partir das ilustrações, utilizando-se a fantasia, a experiência e a vivência da criança. A leitura desse tipo de texto estimula o imaginário infantil, desenvolve a percepção visual e contribui para o desenvolvimento cognitivo e linguístico na medida em que convida a criança a criar a história a partir das ilustrações (Rodrigues, 2004). Na linha de pesquisa que articula o desenvolvimento da linguagem da mente em crianças pré-escolares e a literatura infantil, este estudo teve por objetivo investigar a ocorrência de termos mentais na leitura de um livro de história infantil contendo narrativa por imagem em crianças de 5 e 6 anos de idade.

\section{Método}

\section{Participantes}

Foram selecionados 20 crianças, 10 meninas e 10 meninos, com 6 anos de idade (média de 6 anos e 2 meses) e 20 crianças com 5 anos (média de 5 anos e 2 meses), sendo 11 meninas e 9 meninos de uma escola municipal de educação infantil de uma cidade da zona da mata mineira.

\section{Instrumento}

A seleção do livro envolvendo narrativa por imagem foi feita mediante levantamento junto a instâncias educacionais e catálogos de editoras, considerando critérios de qualidade, livros premiados e adequação à faixa etária das crianças. Como resultado deste levantamento foi selecionado o livro Truks (Furnari, 1998), publicado pela Editora Ática, ganhador no ano de 1998 do prêmio Jabuti (melhor ilustração de livro infantil), e de prêmios hors-concours, nas categorias imagem e livro infantil. O livro conta a história de uma bruxinha sapeca que quis brincar com um leão transformando-o em dragão. Mas, em seguida, ela não consegue reverter o feitiço.

\section{Procedimentos}

Em função da faixa etária delimitada e do número reduzido de crianças da escola, a seleção foi feita segundo critério de conveniência. Obteve-se, na própria escola de educação infantil uma listagem das crianças, considerando nível de escolaridade e faixa etária do $2^{\circ}$ e $3^{\circ}$ período pré-escolar (turno da manhã e tarde). As crianças foram selecionadas mediante adequação à faixa etária pretendida. Houve uma reunião com a diretora da escola para esclarecimento dos objetivos da pesquisa e obediência aos procedimentos estabelecidos pelo comitê de ética em pesquisa com seres humanos. Posteriormente, as professoras também foram informadas quanto à pesquisa. O primeiro contato com as crianças foi feito em sala de aula, esclarecendo-se, de forma lúdica, que algumas seriam sorteadas para participar de um trabalho para a Universidade sobre livros de histórias e que iriam ser chamadas individualmente. Após serem chamadas, procurou-se estabelecer, inicialmente, um bom rapport com as crianças estimulando seu interesse em contar histórias (por meio de gravuras). Após este rapport inicial o livro Truks foi apresentado, sendo solicitado à criança que contasse a história por meio das imagens contidas no livro. As narrativas das crianças foram gravadas para posterior transcrição. Cada pesquisadora ficou responsável por um grupo de 20 crianças.

Apósastranscrições,foramanalisadosseparadamente os relatos da história a partir de uma codificação que visou à identificação de palavras e expressões voltadas para os estados mentais mediante a seguinte taxionomia: termos cognitivos, termos emocionais, termos de desejo/intenção e termos perceptivos. A delimitação destas categorias foi feita a partir de uma conjunção de estudos anteriores (Bretherton \& Beeghly, 1982; Brown \& Dunn, 1991; TagerFlusberg, 1992). Gerou-se um instrumento para facilitar a identificação/ocorrência dos termos mentais presentes nos relatos infantis. Termos cognitivos foram definidos como aqueles que remetem a conhecimento, memória, incerteza, sonho, realidade versus pretensão, utilizados para se referir a seus próprios estados mentais e aos dos outros (Bretherton \& Beeghly, 1982). Termos emocionais, de acordo com TagerFlusberg (1992), referem-se a comportamentos emocionais (por exemplo: abraço, beijo, sorriso, choro etc) e são aqueles referentes a emoções ou sentimentos atuais (por exemplo: amar, gostar, estar feliz, assustar etc). Termos de desejo/ intenção foram identificados pelo uso das palavras desejar, precisar, gostaria, indicando volição, motivação ou pedido de um objeto ou uma ação da parte de outra pessoa (Bretherton \& Beeghly, 1982; Brown \& Dunn, 1991). Termos perceptivos foram definidos como aqueles que fazem referência a percepções atuais e são classificados de acordo com os sentidos: visão, audição, paladar, olfato e tato (Bretherton \& Beeghly, 1982; Tager-Flusberg, 1992). Com base nessas definições, a análise das narrativas infantis foi realizada por um grupo de 3 pessoas (pesquisador e 2 bolsistas) que concordaram entre si quanto à ocorrência e categorização dos termos mentais identificados.

\section{Resultados e Discussão}

Como evidencia a Tabela 1, nas narrativas do grupo de crianças de 5 anos de idade foram encontrados 183 termos denotando estados mentais. Os termos mais empregados foram os de percepção com 96 ocorrências (52,5\%), seguidos dos termos emocionais, com 61 ocorrências (33,5\%), cognitivos com $13(7 \%)$ e os de desejo/intenção também com 13 ocorrências (7\%). O qui-quadrado obtido entre as duas categorias de termos mentais mais evocadas por este grupo de crianças - perceptivos e emocionais - $\left(X^{2} \mathrm{O}\right.$ $=7,8 ; X^{2} c=3,84 ;$ g.l. $\left.=1 ; p=0,05\right)$ indica que houve diferença estatística entre essas duas categorias de termos. Ou seja, nas narrativas das crianças de 5 anos houve predomínio dos termos perceptivos. Nas narrativas produzidas pelo grupo de crianças de 6 anos, foi encontrado um total de 264 termos. Os termos mais evocados também foram os perceptivos com 157 ocorrências (60\%), seguidos dos emocionais com 81 ocorrências (30\%), cognitivos $14(5,5 \%)$ e de desejo/ intenção com apenas 12 ocorrências (4,5\%). 
Tabela 1. Frequência de termos denotando estados mentais evocados pelas crianças de 5 e 6 anos

\begin{tabular}{lcccc}
\hline \multirow{2}{*}{$\begin{array}{l}\text { Categorias de } \\
\text { termos }\end{array}$} & \multicolumn{2}{c}{5 anos $(\mathrm{n}=20)$} & \multicolumn{2}{c}{6 anos $(\mathrm{n}=20)$} \\
\cline { 2 - 5 } & $\mathrm{F}$ & $\%$ & $\mathrm{~F}$ & $\%$ \\
\hline Perceptivos & 96 & 52,5 & 157 & 60 \\
Emocionais & 61 & 33,5 & 81 & 30 \\
Cognitivos & 13 & 7 & 14 & 5,5 \\
Desejo/intenção & 13 & 7 & 12 & 4,5 \\
$1 . \quad$ Total & 183 & 100 & 264 & 100 \\
\hline
\end{tabular}

Fonte: Elaboração dos autores

Considerando o total de termos perceptivos (157) em relação à soma dos totais dos demais termos (107), o quiquadrado obtido $\left(X^{2} \mathrm{O}=9,4\right.$ e $X^{2} \mathrm{C}=3,84 ;$ g.l. $\left.=1 ; p=0,05\right)$ indica que o grupo de 6 anos evocou com mais frequência termos perceptivos. Semelhante ao grupo de crianças de 5 anos de idade, houve diferença estatística entre as duas categorias mais evocadas de termos mentais $\left(X^{2} \mathrm{O}=24,2 ; X^{2} C\right.$ $=3,84 ; \mathrm{g} . \mathrm{I} .=1 ; \mathrm{p}=0,05)$. A frequência de termos perceptivos foi significativamente maior que a de termos emocionais. No grupo de crianças mais velhas a diferença entre o total de termos perceptivos e emocionais evocados foi superior à diferença entre o total de termos perceptivos e emocionais evocados pelas crianças mais novas.

De acordo com Bretherton e Beeghly (1982), a aquisição dos termos pelas crianças segue uma sequência evolutiva que se inicia com os termos perceptivos, uma vez que os primeiros comportamentos das crianças se baseiam na imitação, seguidos por termos emocionais, cognitivos e por fim termos de desejo e intenção. As crianças dos dois grupos refletem uma ordem de evocação de termos mentais semelhante às crianças americanas pesquisadas pelos autores acima referidos. Deve-se atentar, no entanto, para os diferentes contextos culturais onde as pesquisas foram realizadas, pois como ressalta Dias (1993), o uso de termos mentais sofre influência das experiências e interações sociais presentes em cada cultura.

Comparativamente houve diferença estatística entre o total de termos mentais evocados pelas crianças de 5 anos (183 termos) e as de 6 anos (264 termos), $\left(X^{2} O=14,6 ; X^{2} C\right.$ $=3,84 ;$ g.l. $=1 ; p=0,05)$. Ou seja, as crianças de 6 anos evocaram mais termos mentais que as de 5 anos. $O$ cálculo do qui-quadrado em cada categoria, comparando-se os dois grupos, indica diferença estatística no que se refere à utilização dos termos perceptivos $\left(X^{2} O=14,7, X^{2} \mathrm{C}=3,84\right.$; g.I. $=1 ; p=0,05)$. Ainda que o número de termos evocados pelas crianças de 6 anos tenha sido mais expressivo em todas as categorias em relação ao grupo de crianças de 5 anos, houve predominância dos termos perceptivos.

Dos termos perceptivos evocados pelas crianças de 5 anos (96 termos), o mais frequente nas narrativas foi Ver e seus cognatos (p. ex.: vendo, vê, viu) com 51 referências
(53\%), seguido de Olhar e seus cognatos (p.ex.: olha, olhou, olhando) com 44 referências (46\%). 55\% das crianças com 5 anos usaram de 0 a 4 termos perceptivos, 35\% usaram de 5 a 11 termos e $10 \%$ usaram acima de 14 termos perceptivos. Observa-se que essa categoria engloba termos perceptivos os quais envolvem ações observáveis, comuns e mais fáceis de serem identificadas pelas crianças pequenas (Bretherton \& Beeghly, 1982; Tager-Flusberg, 1992). A ocorrência de termos perceptivos nas crianças de 6 anos foi de 157 termos $(60 \%)$. Foram registrados 3 tipos diferentes de palavras (cheirar, olhar e ver). O termo mais frequentemente expresso por este grupo foi Olhar e seus cognatos (p. ex.: olhou, olhando, olha), com 91 referências (57\%), seguido de Ver, com 65 referências (41\%). 25\% das crianças com 6 anos utilizaram 1 a 4 termos perceptivos, 55\% 5 a 11 termos e $15 \%$ evocaram mais de 12 termos perceptivos.

A categoria de termos perceptivos foi, portanto, a mais evocada pelas crianças das duas idades. A ocorrência expressiva de termos perceptivos nos dois grupos de crianças sugere que a leitura das imagens pelas crianças focalizou, preponderantemente, as ações e atos físicos dos personagens em detrimento dos estados subjetivos propriamente (tais como pensamentos, emoções, desejos e intenções). Constatou-se, portanto, uma maior facilidade das crianças em descrever comportamentos observáveis, como as ações dos personagens, do que atitudes envolvendo ações implícitas, não observáveis. Outro aspecto que merece destaque refere-se à quantidade de termos evocados por cada criança nos dois grupos. Na comparação evidencia-se que $55 \%$ das crianças de 5 anos evocou 0 a 4 termos perceptivos e que o mesmo percentual (55\%) de crianças de 6 anos evocou 5 a 11 termos. Esse dado pode evidenciar que o grupo de crianças mais velhas está mais familiarizado e diversifica mais a utilização dos termos perceptivos. Pode-se considerar que as crianças de 6 anos, por serem mais velhas, foram mais expostas a estes termos, incorporando-os ao seu vocabulário cotidiano. É relevante salientar que a estrutura da história do livro Truks apresenta muitas ações executadas pelas personagens expressas nas ilustrações, fato que pode ter contribuído para a evocação predominante de termos perceptivos nos dois grupos de 
crianças. Segundo Dyer e cols. (2000), a grande ocorrência de termos perceptivos nas falas das crianças tem explicação nos primeiros comportamentos de observação, nos quais a criança se fixa nos movimentos físicos e atitudes do outro.

Com relação aos termos emocionais, o grupo de crianças de 5 anos evocou um total de 61 termos (33,5\%), envolvendo 11 palavras diferentes, sendo 5 positivas (33\%), (p.ex.: abraçar, apaixonada, feliz) e 6 negativas (67\%) (p.ex.: chorar, deprimido, triste). O termo emocional mais evocado por este grupo foi Chorar e seus cognatos com 22 ocorrências (37\%). A quase totalidade das crianças com 5 anos (95\%) usaram de 1 a 4 termos emocionais. O grupo de crianças com 6 anos de idade evocou 81 termos emocionais (30\%), utilizando 12 tipos de palavras diferentes divididas em 6 positivas (43\%) (p.ex.: carinho, rir, abraçar) e 5 negativas (57\%) (p.ex.:medo, assustar, bravo). Chorar e seus cognatos (chorando, chorou) foi o termo mais frequente, com 28 ocorrências (34\%). Nesta categoria, $65 \%$ das crianças com 6 anos evocaram 4 a 7 termos emocionais e o restante 1 ou 2 termos. Todas as crianças mais velhas utilizaram termos emocionais em suas narrativas. É importante salientar que as crianças de 5 e 6 anos já adquiriram uma compreensão das suas emoções e das emoções que lhes são externas, visto que já conseguem informar e entender que tipo de emoção o outro pode estar sentindo e que esta pode ser diferente da sua emoção (Rodrigues, 2004). Mas, do ponto de vista evolutivo e do desenvolvimento da teoria da mente, era esperado que houvesse uma diferença mais expressiva na evocação dos termos emocionais entre as crianças dos dois grupos, na medida em que as crianças de 6 anos, presumidamente, já podem ter vivenciado experiências familiares e educacionais mais diversificadas. A ilustração do livro utilizado não apresenta, a princípio, emoções contraditórias, e os estados emocionais das personagens são bem expressados, permitindo uma grande variabilidade de termos emocionais, aspecto que foi realçado nas narrativas de ambas as idades.

Quanto aos termos cognitivos, as crianças com 5 anos evocaram um total de 13 termos (7\%), apresentando 7 tipos diferentes de palavras (descobrir, enfeitiçar, imitar, pensar, perguntar, procurar, tentar). Os dois termos cognitivos mais utilizados por elas foram Pensar e seus cognatos (p.ex: pensa, pensando, pensou) e Procurar e seus cognatos (p.ex.: procura, procurando) com 3 ocorrências (23\%) cada um. Somente $40 \%$ desse grupo (8 crianças) utilizaram de 1 a 3 termos cognitivos, ou seja a maioria (60\%) não utilizou nenhum termo cognitivo em sua narrativa. Agrupando-se os termos semelhantes foram encontrados, nas narrativas das crianças com 6 anos 14 termos cognitivos (5,5\%) e 9 tipos diferentes de termos (saber, achar, acreditar, contar, descobrir, imitar, pensar, procurar, tentar). O termo cognitivo mais evocado por esse grupo foi Tentar e seus cognatos (28,5\%), seguido por Imitar e Procurar (14,3\%). Semelhante ao grupo de 5 anos, $50 \%$ das crianças de 6 anos não evocou termos cognitivos. Segundo Shatz e cols., (1983), os verbos mentais começam a aparecer na fala das crianças a partir do terceiro ano de vida, mas o uso desses termos não se refere necessariamente aos estados e processos internos da criança, ou seja, a criança pode evocar os termos, mas não compreendê-los. Considerando as crianças de 5 anos, esta baixa frequência pode estar relacionada ao nível de desenvolvimento da aquisição de termos cognitivos, visto que estes termos, de acordo com Bretherton e Beeghly (1982) são um dos últimos a serem adquiridos e utilizados na fala cotidiana das crianças. Entretanto, é interessante destacar que não houve diferença na ocorrência de termos cognitivos nos dois grupos. Esperava-se que as narrativas das crianças de 6 anos apresentassem um número mais expressivo de termos cognitivos considerando-se aspectos evolutivos relacionados ao desenvolvimento da teoria da mente, da linguagem e de aspectos contextuais, como a família e, por possuírem um ano a mais de escolaridade. Os resultados, no entanto, foram equivalentes nos dois grupos de crianças. Este resultado pode estar relacionado à estrutura da narrativa do livro utilizado.

$\mathrm{Na}$ codificação dos termos denotando desejo/ intenção nas narrativas das crianças de 5 anos, somente um termo foi encontrado, Querer e seus cognatos, num total de 13 ocorrências. $35 \%$ das crianças com 5 anos evocaram este termo 1 a 4 vezes em suas narrativas; $65 \%$ das crianças não utilizaram nenhum termo denotando desejo/intenção. Resultado semelhante foi obtido com as crianças de 6 anos; foram encontrados 12 termos de desejo/intenção. A palavra Querer e seus cognatos (p.ex.: quer, querendo, quis) foi o termo predominante empregado pelas crianças, com 11 ocorrências (91,6\%). Embora com frequência restrita, 40\% das crianças com 6 anos evocaram termos relacionados a desejo/intenção (30\% evocaram um termo e 10\% três termos). A categoria de termos denotando desejo/intenção foi a menos evocada nos dois grupos. De acordo com Wimmer e Perner (1983), as crianças pré-escolares apresentam uma maior dificuldade para expressar e antecipar intenções e desejos dos outros. Segundo Ottoni, Rodriguez e Barreto (2006), a compreensão de crenças de $2^{\mathrm{a}}$ e $3^{\mathrm{a}}$ ordem tendem a se consolidar aos 9 anos de idade o que realça, portanto a dificuldade que estas crianças apresentam ao expressar desejos e intenções.

\section{Considerações Finais}

Os resultados encontrados nesta pesquisa indicam que as crianças de 5 e 6 anos já apresentam em sua fala cotidiana termos referentes a estados mentais. A evocação destes termos informa sobre a linguagem da mente das crianças pré-escolares que, de acordo com Astington e Pelletier (2000) e Souza $(2006,2008)$ quando bem desenvolvida, facilita o processo de aprendizagem e a socialização da criança, ou seja, a compreensão do mundo.

Os resultados indicam que as crianças da presente pesquisa focalizaram mais em suas narrativas termos perceptivos, no entanto é preciso destacar que esta evocação pode estar vinculada à estrutura da narrativa por imagens oferecida pelo livro infantil utilizado. Mais 
pesquisas são necessárias com a utilização de outros livros com ênfases diferenciadas e com pré-escolares de escolas da rede privada.

É importante destacar também a necessidade de uma maior estimulação dos termos cognitivos, emocionais e voltados para desejo e intenção no cotidiano da vida das crianças, pois a relação social é importante na estimulação da linguagem. É por meio da linguagem que a criança aprende a expressar seus sentimentos, explicar suas reações e compreender as dos outros, conhecer diferentes pontos de vista sobre um mesmo fato e incorporar valores e normas sociais. Astington e Pelletier (2000) argumentam que a linguagem da mente é necessária à maturidade social, à aprendizagem cooperativa, à monitoração da própria atividade cognitiva, para a geração e teste de hipóteses científicas, para falar sobre o que os personagens de histórias estão fazendo e para a discussão das motivações de personagens literários e históricos.

Para todos esses fins, é necessário que a teoria da mente das crianças seja expressa por meio da linguagem e que esta seja estimulada na família e na escola. De acordo com as autoras citadas, a família e a escola possuem papel relevante na aquisição de uma linguagem da mente. Crianças que possuem uma teoria da mente bem desenvolvida podem ter maior facilidade nas atividades escolares. Conversas em casa sobre diferentes perspectivas auxiliam as crianças na compreensão de que as pessoas podem ter crenças diferentes sobre o mundo e que essas crenças podem mudar, favorecendo a apreensão do conhecimento transmitido pelo professor na medida em que a criança é capaz de formar e revisar este conhecimento sobre o mundo, tornando esta atividade mais fácil para a criança.

Concorda-se com Lyra, Roazzi e Garvey (2008), quanto à importância da dimensão social como "aspecto vital e intrinsecamente relacionado ao processo de desenvolvimento cognitivo mais geral, e da aquisição da teoria da mente, em particular" (p. 85). Conclui-se que é fundamental que a linguagem da mente, ou seja, a linguagem voltada para o conhecimento e compreensão dos estados mentais, seja estimulada e promovida no âmbito da educação infantil.

\section{Referências}

Astington, J. W., \& Pelletier, J. (2000). A linguagem da mente: seu papel no ensino e na aprendizagem. Em D. R. Olson \& N. Torrance (Orgs.), Educação e desenvolvimento humano (pp. 489-510). Porto Alegre: Artmed.

Astington, J. W., \& Baird, J. (2005). Why language matters for theory of mind. New York: Oxford University Press.

Bretherton, I., \& Beeghly, Y. M. (1982). Talking about internal states: The acquision of an explicity Theory of Mind. Developmental Psychology, 18, 906-921.

Brown, J. R., \& Dunn, J. (1991). "You can cry, mum": The social and development implications of talk about internal states. British Journal of Development Psychology, 9, 237-256.
Cassidy, K. W., Ball, L. V., Rourke, M. T., Werner, R. S., Feeny, N., Chu, J. Y., Lutz, D. J., \& Perkins, A. (1998). Theory of mind concepts in children's literature. Applied Psycholinguistics, 19, 463-470.

Catálogo Literatura Infantil. (2005). São Paulo: Ática.

De Jou G. I., \& Sperb, T. M. (1999). Teoria da mente: diferentes abordagens. Psicologia: Reflexão e Crítica, 12(2), 287-306.

Dias, M. G. B. B. (1993). O desenvolvimento do conhecimento da criança sobre a mente. Psicologia: Teoria e Pesquisa, 9(2), 587600.

Dias, M. G. B. B., Soares, G. B., \& Sá, T. P. (1994). Conhecimento sobre a mente e compreensão sobre as intenções do experimentador. Psicologia: Teoria e Pesquisa, 10 (4), 221-229.

Domingues, S. F. S., \& Maluf, M. R. (2008). Compreendendo estados mentais: procedimentos de pesquisa a partir da tarefa original de crença falsa. Em T. M. Sperb \& M. R. Maluf (Orgs.), Desenvolvimento sociocognitivo. Estudos brasileiros sobre "Teoria da Mente" (pp. 11-31). São Paulo: Vetor Editora.

Dunn, J., Bretherton, I., \& Munn, P. (1987). Conversations about feeling states between mothers and their young children. Developmental Psychology, 23(1), 132-139.

Dyer, J. R., Shatz, M., \& Wellman, H. M. (2000). Young children's storybooks as a source of mental state information. Cognitive Development, 15(1), 17-37.

Flavell, J. H., Miller, P. H., \& Miller, A. S. (1999). Desenvolvimento cognitivo (3a ed.). (C. Dornelles, Trad.). Porto Alegre: Artmed. (Trabalho original publicado em 1993). (Trabalho original publicado em 1993)

Furnari, E. (1998). Truks. São Paulo: Ática.

Levin, J. (1987). Estatística Aplicada a Ciências Humanas. (2a ed.). São Paulo: Harbra.

Lyra, V. P., Roazzi, A., \& Garvey, A. P. (2008). Emergência da teoria da mente em relações sociais. Em T. M. Sperb \& M. R. Maluf (Orgs.), Desenvolvimento sociocognitivo. Estudos brasileiros sobre "Teoria da Mente" (pp. 55-91). São Paulo: Vetor.

Lourenço, O. (1992). Teorias da mente na criança e o desenvolvimento de crenças falsas: Falsas de quem?. Análise Psicológica, 4(1), 431-442.

Maluf, M. R., Deleau, M., Panciera, S. D. P., Valério, A., \& Dominguez, S. F. S. (2004). A teoria da mente: mais um passo na compreensão da mente das crianças. Em M. R. Maluf (Org.), Psicologia educacional: questões contemporâneas (pp. 09-222). São Paulo: Casa do Psicólogo.

Ottoni, E. B., Rodriguez, C. F., \& Barreto, J. C. (2006). Teoria da Mente e compreensão da representação gráfica de conteúdos mentais ("balões de pensamento"). Interação em Psicologia, 10(2), 225-234.

Roazzi, A., \& Santana, S. M. (1999). Teoria da mente: efeito da idade, do sexo e do uso de atores animados e inanimados na inferência de estados mentais. Psicologia: Reflexão e Crítica, 12(2), 307-330.

Roazzi, A., \& Santana, S. M. (2005). Cognição social em crianças: descobrindo a influência de crenças falsas e emoções no comportamento humano. Psicologia: Reflexão e Crítica, 19(1), $1-8$

Rodrigues, M. C. (2004). Concepções docentes pré-escolares sobre teorias da mente e sociocognitiva aplicadas: histórias infantis. Tese de Doutorado, Pontifícia Universidade Católica de Campinas, Campinas, São Paulo. 
Rodrigues, M. C., Oliveira, P. A., Rubac, J. S., \& Tavares, A. L. (2007). Literatura infantil, teoria da mente e processamento de informação social. Psicologia Escolar e Educacional, 11(1), 7788.

Souza, D. H. (2006). Falando sobre a mente: Algumas considerações sobre a relação entre linguagem e teoria da mente. Psicologia: Reflexão e Crítica, 19(3), 387-394.

Souza, D. H. (2008). De onde e para onde? As interfaces entre linguagem, teoria da mente e desenvolvimento social. Em T. M. Sperb \& M. R. Maluf (Orgs.), Desenvolvimento sociocognitivo. Estudos brasileiros sobre "Teoria da Mente" (pp. 33-54). São Paulo: Vetor.
Shatz, M., Wellman, W. M., \& Silber, S. (1983). The acquision of mental verbs: A systematic investigation of first reference to metal state. Cognition, 14, 301-321.

Tager-Flusberg, H. (1992). Autistic children talk about psychological states: Deficits in the early acquision of theory of mind. Child Development, 63, 161-172.

Vale, L. V. (2001). Narrativas infantis. Em J. A. Saraiva (Org.), Literatura e alfabetização (pp. 43-49). Porto Alegre: Artmed.

Villardi, R. (1999). Ensinado a gostar de ler e formando leitores para a vida inteira. Rio de Janeiro: Dunya.

Wimmer, H., \& Perner, J. (1983). Beliefs about beliefs: Representation and constraining function of wrong beliefs in Young children's understanding of deception. Cognition, 13, 103-128.

Recebido em: 26/11/2007

Reformulado em: 26/05/2009

Aprovado em: 17/07/2009

\section{Sobre as Autoras}

\section{Marisa Cosenza Rodrigues}

Doutora em Psicologia pela Pontifícia Universidade Católica de Campinas - SP e Docente do Departamento de Psicologia da Universidade Federal de Juiz de Fora.

\section{Mariana Wierman Henriques}

Graduanda em Psicologia na Universidade Federal de Juiz de Fora

Bolsista de Iniciação Científica do BIC/UFJF.

Marina de Oliveira Patrício, Graduanda em Psicologia na Universidade Federal de Juiz de Fora

Bolsista de Iniciação Científica PROVOQUE/PROPESQ-UFJF.

Apoio Financeiro: PROPESQ/UFJF 